Article

\title{
Research on Digital Synchronous Rectification for a High-Efficiency DC-DC Converter in an Auxiliary Power Supply System of Magnetic Levitation
}

\author{
Zhiqin Zhao ${ }^{1}$ (1) and Xiaoqiong $\mathrm{He}^{1,2, *}$ \\ 1 School of Electrical Engineering, Southwest Jiaotong University, Chengdu 611756, China; \\ 563199973@my.swjtu.edu.cn \\ 2 National Rail Transit Electrification and Automation Engineering Technique Research Center, Southwest \\ Jiaotong University, Chengdu 611756, China \\ * Correspondence: hexq@swjtu.edu.cn; Tel.: +86-136-0809-8778
}

Received: 25 November 2019; Accepted: 17 December 2019; Published: 20 December 2019

\begin{abstract}
In this paper, a new auxiliary power supply system of magnetic levitation based on the LLC DC-DC converter is proposed. The switches of the DC-DC converter are SiC MOSFET, which enables high frequency, high temperature, and high power density. For further improving the efficiency of the system and realizing the stability of the output voltage under different load conditions, the digital synchronous rectification (DSR) based on the phase shift control strategy is proposed. The prototype of the LLC DC-DC converter based on SiC MOSFET is implemented, which can realize zero voltage switching (ZVS) and zero current switching (ZCS). Then, the thermal image of DSR is presented, which proves that the power loss of SiC MOSFET with DSR is relatively low. Additionally, the system efficiency among the Si IGBT, SiC MOSFET, and SiC MOSFET with DSR is analyzed and the prototype demonstrates $98 \%$ peak efficiency. Finally, simulations, experiments, and data analysis prove the superiority of the proposed DSR strategy for the new auxiliary power supply system of magnetic levitation.
\end{abstract}

Keywords: digital synchronous rectification; LLC DC-DC converter; SiC MOSFET; phase shift control; auxiliary power supply system

\section{Introduction}

With the rapid development of China's economy, the urban railway system has earned worldwide plaudits for its efficiency, reliability, and portability. The magnetic levitation train is an important part of the urban railway system, which has been widely studied and applied in recent years [1,2]. The existing magnetic levitation power supply system is illustrated in Figure 1, including the auxiliary power supply system, traction converter module, and suspension control module. The DC traction network is the input of the magnetic levitation train power supply system. Under stable states, the input voltage of the DC traction network is $1500 \mathrm{~V}$. However, the maximum input voltage may be over $1800 \mathrm{~V}$ and the minimum input voltage may be less than $1000 \mathrm{~V}$ in operation. The auxiliary power supply system is the key power supply equipment for the magnetic levitation train, which provides power for air conditioning, lighting, and ventilation. Whereas, the existing auxiliary power supply system in the magnetic levitation train has the disadvantage of being bulky and inefficient. How to improve the efficiency of the system and how to reduce the volume and weight of the auxiliary power supply system have been a major design challenge [3,4]. 


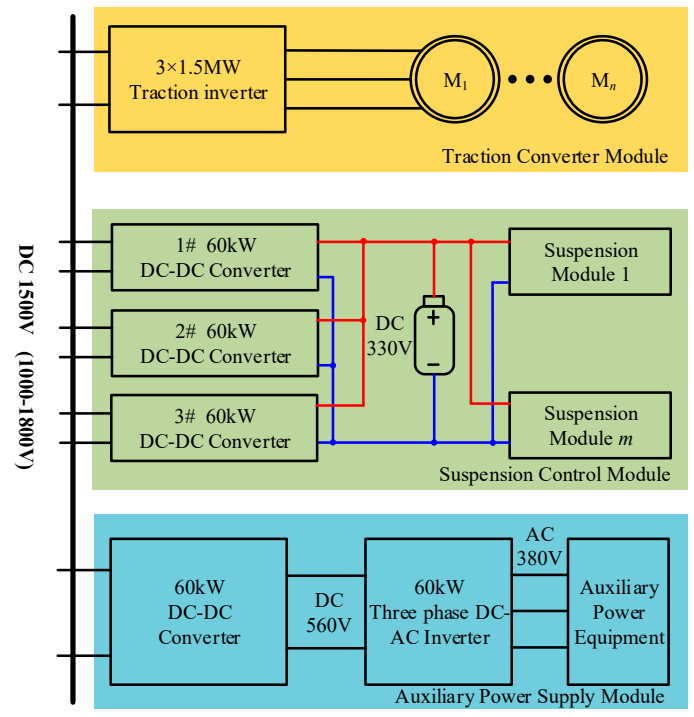

Figure 1. Existing magnetic levitation power supply system.

At present, the auxiliary power supply system of the magnetic levitation train is composed of the $60 \mathrm{~kW}$ DC-DC converter and the $60 \mathrm{~kW}$ DC-AC converter. Si IGBT is the most widely used switching device in the existing magnetic levitation power supply system. However, the converters with Si IGBTs have difficulties acquiring the high efficiency and power density, due to the voltage withstanding and frequency-tolerance characteristics of Si IGBTs [5,6]. Switching losses will account for more than $20 \%$ of the auxiliary power supply system. With the research of the third-generation wide bandgap semiconductor devices, $\mathrm{SiC}$ MOSFET is widely used in power electronics converters. The outstanding performance of $\mathrm{SiC}$ MOSFET modules on low-power applications is verified with the energy losses and the thermal models [7-10]. However, SiC MOSFET is rarely used in high-power applications, especially in rail vehicles.

Although SiC MOSFET already has good efficiency performance, to further reduce switching losses, several switching techniques have been proposed to achieve soft switching in the DC-DC converter [11-25]. In these techniques, the semiconductor devices turn ON or OFF when the voltage is zero, presenting zero voltage switching (ZVS), or when the current is zero, presenting zero current switching (ZCS) [11-13]. Switching losses can be greatly reduced by ZVS and ZCS, which can be achieved by control strategies and resonant circuits. The resonant circuits can be classified into the series resonant converter (SRC), parallel resonant converter (PRC), and serial-parallel resonant converter [14]. In Reference [15], a half-bridge resonant DC-DC converter is proposed for modern computing systems, which implements the ZVS. However, the proposed series resonant converter cannot acquire ZVS in the entire power range. Additionally, the controller suffers the wide range of switching frequency and the output voltage cannot be regulated at no load. In Reference [16], a PRC is researched for high-voltage applications to extend the ZVS range. However, the relatively large power losses under the light load condition are not changed. A LLC DC-DC converter is a typical series-parallel converter which is composed of two inductive components and one capacitive component. To improve the performance of SRC and PRC, an asymmetric LLC DC-DC converter is proposed in Reference [17]. The converter operates at a constant frequency and adjusts the duty cycle to regulate the voltage gain with a wide range. However, the transformer with a center tap is inconvenient for bidirectional power transmission. In Reference [18], the proposed LLC DC-DC converter has a wide input range and could realize the soft switching under all conditions. In addition, with the property of ZVS and ZCS, electromagnetic interference can be reduced by the LLC DC-DC converters. Consequently, the LLC DC-DC converter is popular for its high efficiency, high reliability, and low loss [17-20]. Benefiting from the advantages mentioned above, a magnetic levitation power supply system based on the LLC DC-DC converter is proposed in this paper. 
In order to further improve the efficiency of the LLC DC-DC converter, synchronous rectification (SR) is a popular method to reduce the secondary conduction loss [21-23]. The definition of SR is replacing the original secondary diode by low resistance switches and realizing the control of synchronous switching. However, due to the discrepancy between the primary driving signal and the SR driving signal, the SR driving solution is quite a challenge, especially under high voltage. Nowadays, most of the SR driving schemes are based on SR chips, which are suitable for low-voltage and low-power applications [23]; whereas, the SR chip cannot apply to high-voltage and high-power applications, such as the magnetic levitation power supply system. In Reference [24], many SR switches are utilized in parallel to reduce the conduction loss in the secondary sides. However, the parasitic capacitance will be larger and it results in complex designs of the resonant tank and a severe regulation problem of the LLC DC-DC converter. Thus, a new digital synchronous rectification (DSR) strategy is defined in Reference [25], which controls the SR switches by digital logic without any additional component. The new strategy achieves the output voltage regulation and high efficiency in the light-load condition. However, the method is only suitable for a special asymmetric serial-parallel resonant converter with a center tap transformer. Moreover, there are few studies on the DSR strategy in high-power applications. Therefore, it is necessary to further study the DSR strategy for the LLC DC-DC converter [26-33].

In this paper, a new auxiliary power supply system of magnetic levitation based on the LLC DC-DC converter is presented. Compared with the previous system, the new auxiliary power supply system has higher efficiency and smaller volume. The DSR strategy is proposed to reduce the switching loss, whereas the SiC MOSFET is utilized to reduce the volume of magnetic components and radiators. The rest of this paper is organized as follows. In Section 2, the structure and the working state of the LLC DC-DC converter are analyzed. In Section 3, a mathematical model of the LLC DC-DC converter is established by fundamental harmonic approximation (FHA). The DC gain function with four parameters is derived and the DC gain curve is drawn with different parameters. In Section 4, the SR technique and PWM (Pulse width modulation) control strategy are designed. On the basis of the theoretical analysis, the experimental results are given to validate the proposed new auxiliary power supply system in Section 5. The conclusion is summarized in Section 6.

\section{System Configurations}

\subsection{Structure of the LLC DC-DC Converter}

Figure 2 shows the topological structure of the LLC DC-DC converter, which is used in an auxiliary power supply system of magnetic levitation. The LLC DC-DC converter is considered to be composed of four parts, including switching network, resonant tank, ideal transformer, and rectifying network. The input voltage is $V_{\text {in }}$ and the output voltage is $V_{o}$.

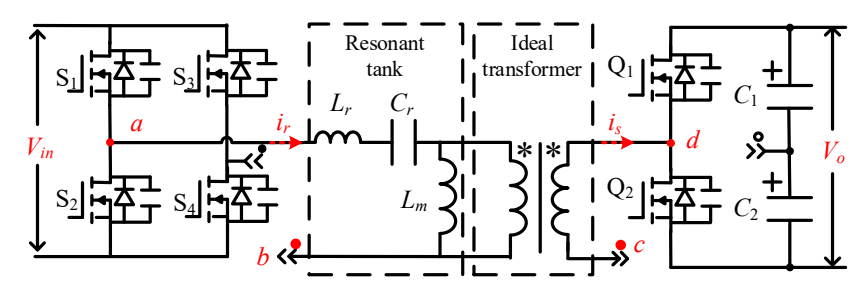

Figure 2. Topology of the LLC DC-DC converter.

The resonant tank is the most important part to realize ZVS and ZCS, which is composed of a resonant capacitor $C_{r}$, a series resonant inductor $L_{r}$, and a parallel resonant inductor $L_{m}$. The first resonant frequency $f_{r}$ and the second resonant frequency $f_{m}$ are defined as: 


$$
\left\{\begin{array}{l}
f_{r}=\frac{1}{2 \pi \sqrt{L_{r} C_{r}}} \\
f_{m}=\frac{1}{2 \pi \sqrt{\left(L_{r}+L_{m}\right) C_{r}}}
\end{array}\right.
$$

In order to achieve soft switching, the normal operating frequency range of the LLC DC-DC converter is actually in the range of $f_{m}<f_{s w}<f_{r}$, where $f_{s w}$ is the working frequency.

\subsection{Operation Principle}

Six working states of the LLC DC-DC converter are illustrated in Figure 3. The working waveforms of the LLC DC-DC converter are shown in Figure 4, which is corresponding to the six working states. $\mathrm{g}_{1,4}$ and $\mathrm{g}_{2,3}$ are the driving signals of the $S_{1}, S_{2}, S_{3}$, and $S_{4} . V_{a b}$ is the voltage between point a and point b. $i_{L m}$ and $i_{L r}$ are the current of the $L_{m}$ and $L_{r} . i_{Q 1,2}$ is the current of the $Q_{1}$ and $Q_{2} \cdot V_{C 1,2}$ is the voltage of the $C_{1}$ and $C_{2}$. The operation principles are analyzed as follows.
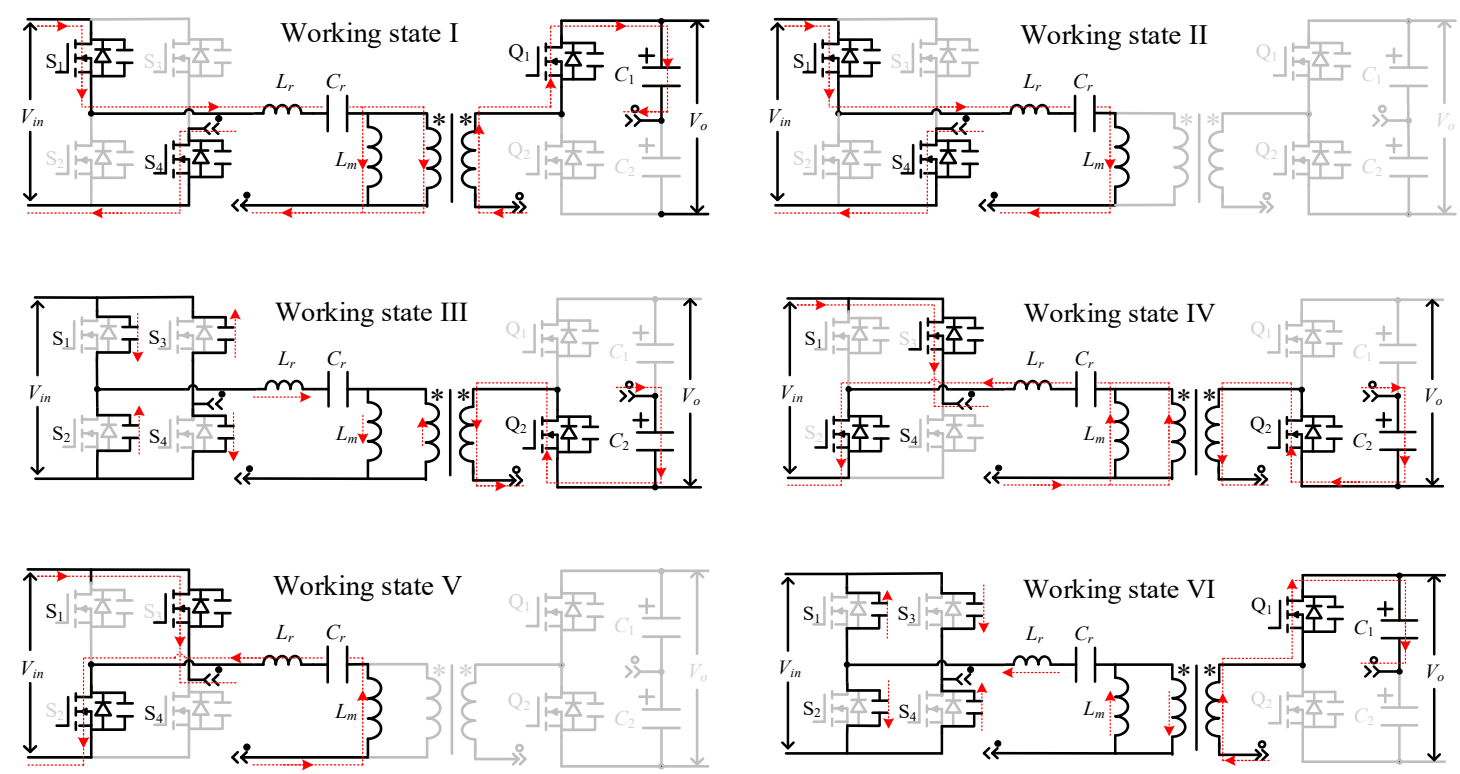

Figure 3. Working states of the LLC DC-DC converter $\left(f_{m}<f_{s w}<f_{r}\right)$.

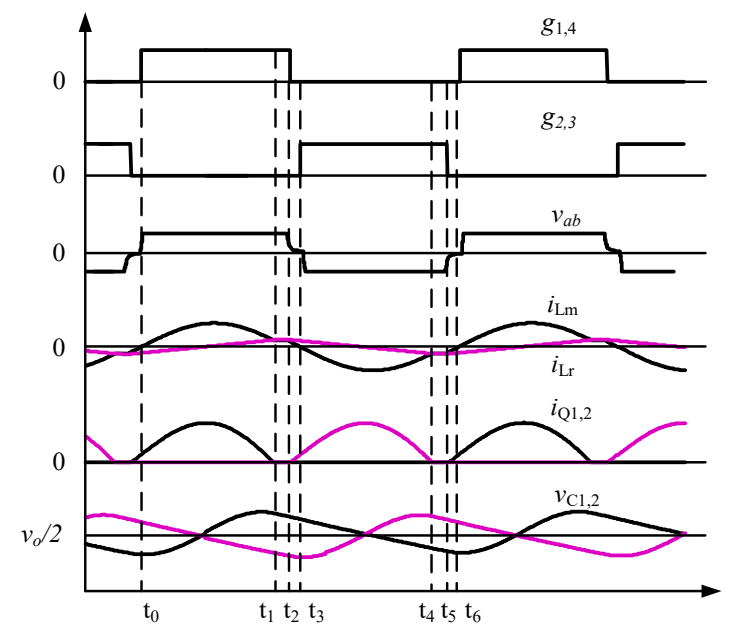

Figure 4. Working waveforms of the LLC DC-DC converter $\left(f_{m}<f_{s w}<f_{r}\right)$.

- Working state I $\left(t_{0}-t_{1}\right)$. 
At $t_{0}$, the $g_{1,4}$ is at a high level and the switch signals of $S_{1}$ and $S_{4}$ are on. Due to the fact that $i_{L m}$ cannot be abrupt, there will be part of the primary current flowing through the transformer, which will make the secondary side produce an induced current. Then, the switch signal of $Q_{1}$ is on, the $C_{1}$ is charged, and the $C_{2}$ is not charged. The load is supplied by the power of $C_{1}$ and $C_{2} \cdot i_{L m}$ is in a linear rising phase. At this time, $L_{m}$ does not participate in resonance, and the components participating in the resonance are $L_{r}$ and $C_{r}$ until time $t_{1}$.

- Working state II $\left(t_{1}-t_{2}\right)$.

At $t_{1}$, the $g_{1,4}$ is at a high level and the switch $S_{1}$ and $S_{4}$ are still working. The $i_{L r}$ decrease to the $i_{L m}$ and then keep this state until $t_{2}$. The current flow through the transformer is equal to zero so that the primary and secondary sides of the transformer are isolated. The load is supplied by the power of $C_{1}$ and $C_{2}$. In this state, $L_{m}, L_{r}$, and $C_{r}$ participate in resonance.

- Working state III $\left(t_{2}-t_{3}\right)$.

At $t_{2}$, the $g_{1,4}$ and $g_{2,3}$ are at low levels and none of the switches are working. The $i_{L r}$ is gradually reduced to zero so that the resonant network and the input power are isolated. In this state, the voltage drops of the parasitic capacitances for primary-side switches are different, which is propitious to the realization of ZVS and ZCS. Part of the primary current flows through the transformer, and the corresponding current is induced at the secondary side. Then, the $Q_{2}$ is on, the $C_{2}$ is charged, and the $C_{1}$ is not charged.

Working state IV $\left(t_{3}-t_{4}\right)$, working state $\mathrm{V}\left(t_{4}-t_{5}\right)$, and working state VI $\left(t_{5}-t_{6}\right)$ are similar to the working state I-III except for the current direction. The results can be obtained by a similar deduction.

\section{Mathematical Model}

\subsection{Mathematical Model of the LLC DC-DC Converter}

The first step of modeling the resonant DC-DC converter is assuming that,

1. The mid-frequency transformer, switches (IGBT or MOSFET), rectify diodes, inductors, and capacitors, are all ideal devices.

2. The parasitic capacitor is not included in the resonant tank when the working frequency is low.

3. The output voltage ripple is very small, so the output voltage can be considered as DC voltage.

4. Ignore the harmonic of switching frequency.

There are two sets of switches in the full-bridge type and each set of two switches are alternately turned on at a duty cycle of $50 \%$. Therefore, the input voltage $v_{a b}$ of the resonant network is a square wave with an amplitude of $\pm V_{i n}$. The input voltage $v_{a b}$ of the resonant tank of the full-bridge LLC DC-DC converter can be expanded in Fourier form [26].

$$
v_{a b}(t)=\frac{4}{\pi} V_{i n} \sum_{n=1,3,5} \frac{\sin \left(2 n \pi f_{s w} t\right)}{n},
$$

where $V_{\text {in }}$ is the value of the input voltage, $n$ is the multiple of Fourier form, and $f_{s w}$ is the switching frequency.

The fundamental component of $v_{a b}$ is $v_{a b(F H A)}(n=1$, the same direction as the original square wave).

$$
v_{a b(F H A)}(t)=\frac{4}{\pi} V_{i n} \sin \left(2 \pi f_{s w} t\right)
$$

The root mean square (RMS) of $v_{a b(F H A)}$ is $V_{a b(F H A)}$.

$$
V_{a b(F H A)}=\frac{2 \sqrt{2}}{\pi} V_{i n}
$$


$i_{r}$ is the primary current, which is a sinusoidal variation. Assuming that the RMS of $i_{r}$ is $I_{r}$, the difference between the phase of the current and voltage of the cavity is $\theta$.

$$
i_{r}(t)=\sqrt{2} I_{r} \sin \left(2 \pi f_{s w} t-\theta\right),
$$

The current lags or leads the input voltage, which depends on the operating frequency of the resonant tank. Consequently, it causes the circuit to be in an inductive or capacitive state. In any case, the wave of $i_{r}(t)$ can be thought of as a superposition of two different waves. The phase of the first wave is in the same direction as the wave of input voltage $v_{a b}$, and the phase of the second wave is within $\pm 90^{\circ}$ on the basis of the first wave. The idea of superposition promotes the establishment of equivalent circuit and mathematical model. $I_{\text {in }}$ is the input current of the DC power supply system, which is present during the half cycle of the upper half of the bridge arm.

$$
I_{i n}=\frac{2}{T_{s w}} \int_{0}^{\frac{T_{s w}}{2}} i_{r}(t) d t=\frac{2 \sqrt{2}}{\pi} I_{r} \cos \theta,
$$

where $T_{s w}$ is the switching period.

In this paper, $P_{i n}$ is the input power of the resonant tank, which can be calculated by $v_{a b}$ and $i_{r}$. According to Figure 4, the fundamental wave of voltage and the wave of input current are sinusoidal. As a result, the input power $P_{\text {in }}$ can be described as Equation (6).

$$
P_{i n}=\int_{-2}^{T_{\text {sww }}} v_{a b} v_{a b}(t) \cdot i_{r}(t) d t=V_{a b(F H A)} I_{r} \cos \theta,
$$

$v_{c d}$ is the input voltage of the rectifying network. In the secondary side circuit of the transformer, the rectifier diode is driven by the flowing current. When the current is zero, the voltage is reversed. Therefore, $v_{c d}$ is an alternating square wave of which the value of the amplitude is $\pm V_{o} / 2$. The phase of $v_{c d}$ is the same as the current phase of the rectifier circuit. $v_{c d}$ is obtained by Fourier series expansion, which is shown in Equation (7).

$$
v_{c d}(t)=\frac{2}{\pi} V_{o} \sum_{n=1,3,5 \ldots} \frac{\sin \left(2 n \pi f_{s w} t-\psi\right)}{n},
$$

where $\psi$ is the phase difference between the secondary voltage of the transformer $v_{c d}$ and the input voltage of the resonant tank $v_{a b} . V_{o}$ is the output voltage of the LLC DC-DC converter.

The fundamental component of $v_{c d}$ is $v_{c d(F H A)}(n=1$, the same direction as the original square wave).

$$
v_{c d(F H A)}(t)=\frac{2}{\pi} V_{o} \sin \left(2 \pi f_{s w} t-\psi\right),
$$

$V_{c d(\mathrm{FHA})}$ is the RMS value of $v_{c d(F H A)}$, which is shown in Equation (9).

$$
V_{c d(F H A)}=\frac{\sqrt{2}}{\pi} V_{o}
$$

$i_{S}$ is the secondary side current of the transform. $I_{S}$ is the RMS value of the $i_{S} . i_{S}$ can be represented by Equation (10).

$$
i_{s}(t)=\sqrt{2} I_{s} \sin \left(2 n \pi f_{s w} t-\psi\right),
$$

In this paper, $i_{o}$ is the output current of the load. According to the analysis above, the amplitude value of $i_{o}$ is the same as $i_{s}$. The direction of $i_{o}$ is not changed, which can be expressed as $i_{o}=\left|i_{s}\right|$. Therefore, the mean value of $i_{0}$ is shown in Equation (11). 


$$
I_{o}=\frac{2}{T} \int_{0}^{\frac{T}{2}}\left|i_{s}(t)\right| d t=\frac{\pi}{2 \sqrt{2}} I_{s}=\frac{\pi}{2 \sqrt{2}} \frac{V_{o}}{R_{o}}
$$

where $R_{o}$ is the value of the load resistance.

From the previous analysis, it can be seen that $i_{s}$ and $v_{c d}$ are in the same direction. Thereby, the secondary side rectifier circuit can be regarded as an equivalent resistance. The value of the equivalent resistance is $R_{o(\mathrm{eq})}$, which is shown in Equation (12).

$$
R_{o(\mathrm{eq})}=\frac{V_{c d(F H A)}(\mathrm{t})}{i_{S}(\mathrm{t})}=\frac{V_{c d(F H A)}}{I_{o}}=\frac{4}{\pi^{2}} \frac{V_{o}^{2}}{P_{o}}=\frac{4}{\pi^{2}} R_{o}
$$

where $I_{0}$ is the mean value of the output current.

The load is equivalent to the primary side of the transformer. The value of the load $R_{e q}$ can be defined as Equation (13).

$$
R_{e q}=k^{2} R_{o(\mathrm{eq})}=\frac{4 k^{2}}{\pi^{2}} R_{o}
$$

where $k$ is the ratio of the isolated transformer.

Figure 5 is the AC equivalent model of the LLC DC-DC converter. $R_{s}, R_{L}, R_{L m}, R_{\text {eqs }}$, and $R_{c}$ are the parasitic resistance of the resonant tank and switches, which have negligible impacts on the FHA model and power transmission. $C_{\mathrm{s}}$ is the parasitic capacitance of the primary switches, which can usually be ignored [27]. According to the analysis above, the equivalent cavity system and its transfer function can be calculated by Equation (14).

$$
H(s)=\frac{k V_{o(F H A)}(\mathrm{s})}{V_{i n(F H A)}(\mathrm{s})}=\frac{R_{e q} / / s L_{m}}{\frac{1}{s C_{r}}+s L_{r}+R_{e q} / / s L_{m}},
$$

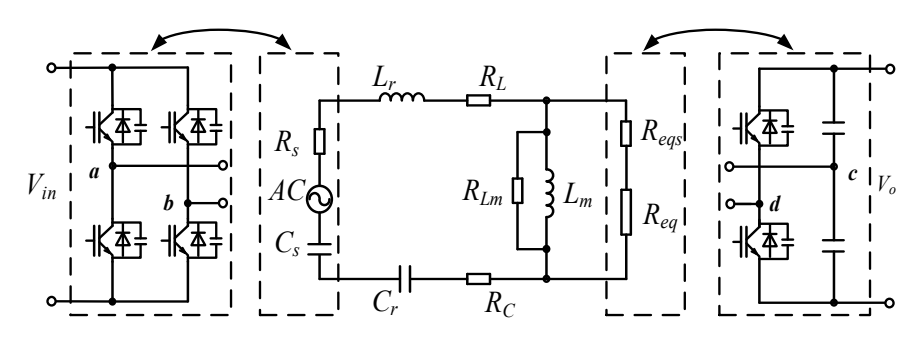

Figure 5. AC equivalent model of the LLC converter.

$M$ is the voltage gain, which can be expressed as Equation (15).

$$
M=\frac{V_{o}}{V_{\text {in }}}=\frac{\frac{\pi V_{c d(F H A)}}{\sqrt{2}}}{\frac{\pi V_{i n(F H A)}}{2 \sqrt{2}}}=\frac{2 V_{c d(F H A)}}{V_{\text {in }(F H A)}},
$$

To simplify the voltage gain expression, the definition is made as follows: $Z_{0}$ is the characteristic impedance, which is illustrated in Equation (16).

$$
Z_{0}=\sqrt{\frac{L_{r}}{C_{r}}}=2 \pi f_{r} L_{r}=\frac{1}{2 \pi f_{r} C_{r}},
$$

$Q$ is the quality factor, which is shown in Equation (17).

$$
Q=\frac{Z_{0}}{R_{e q}}
$$


$\lambda$ is the inductor coefficient, which is shown in Equation (18).

$$
\lambda=\frac{L_{r}}{L_{m}},
$$

$f_{n}$ is the normalized frequency, which is shown in Equation (19).

$$
f_{n}=\frac{f_{s w}}{f_{r}}
$$

According to Equations (15) to (19), $M$ can be simplified as Equation (20).

$$
\begin{aligned}
M & =\frac{V_{o}}{V_{i n}} \\
& =\frac{1}{2 k}\left|\frac{1}{1+\lambda\left(1-1 / f_{n}^{2}\right)+j\left(f_{n}-1 / f_{n}\right) Q}\right| \\
& =\frac{1}{2 k} \frac{1}{\sqrt{\left(1+\lambda\left(1-1 / f_{n}^{2}\right)\right)^{2}+\left(f_{n}-1 / f_{n}\right)^{2} Q^{2}}}
\end{aligned}
$$

Ignoring the transformer ratio $n$ (when $n=1$ ), it can be known that there are three variables in Equation (20), which are $\lambda, f_{n}$, and $Q$. In Figures 6 and 7, the $x$ axis is the normalized frequency $f_{n}$, and the $y$ axis is the voltage gain $M$. $M$ changes when quality factor $Q$ and inductor coefficient $\lambda$ change, respectively.

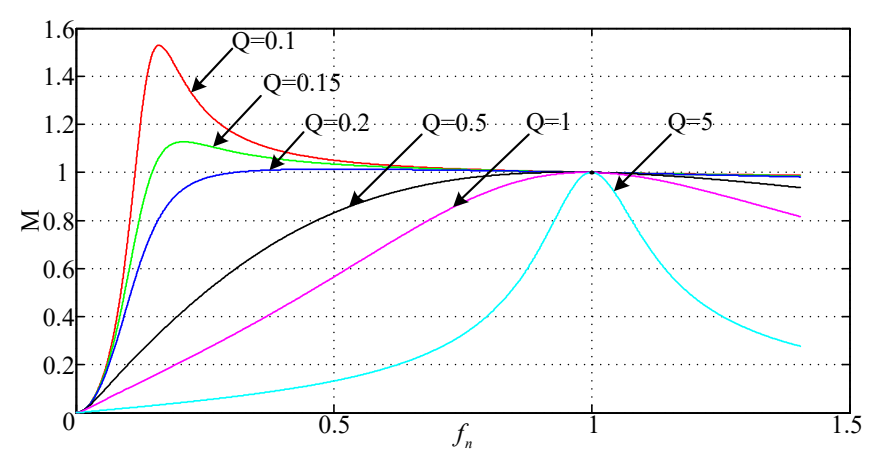

Figure 6. LLC DC-DC converter gain characteristic $(n=1, \lambda=0.02)$.

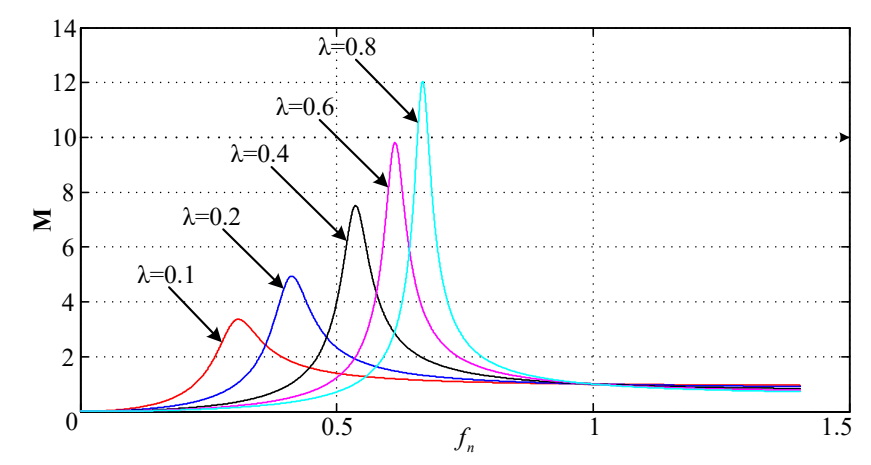

Figure 7. LLC DC-DC converter gain characteristic $(n=1, Q=0.1)$.

\subsection{Voltage Gain Analysis}

In Figure 6, the curve of $M$ changes gently with quality, $Q$, increasing. In the same switching frequency, $M$ is decreasing during the load changed, which is the process of the light load to heavy load. With the increase of normalized frequency, the wave of DC gain has a maxima point. The corresponding frequency of the turning point is determined by the quality, $Q$, as shown in Figure 6.

The operating characteristics of the converter with different switching frequencies are various, as it is a series resonant system. When $f_{n}=1$, the resonant tank is inductive, which ensures the 
implementation of primary ZVS. When $f_{n}>1$, the resonant tank is still inductive. When $f_{n}<1$, the characteristic of the resonant tank is determined by switching frequency and load. When $f_{n}$ is smaller than the frequency of the maxima point, the characteristic of the resonant tank turns to conductive, which leads to the increasing loss of primary switches and the risk of control failure.

With the increase of the inductor coefficient $\lambda$, the dc voltage gain curve becomes steep. The choice of resonant inductance determines the range of switching frequency and the range of output voltage. If the inductor coefficient is too low, the converter may face the risk of overvoltage. If the inductor coefficient is too high, the voltage gain cannot meet the regulation of output voltage, which leads to very low switching frequency or control failure. Therefore, the practical request should be considered when choosing the inductor coefficient $\lambda$.

\section{Digital Synchronous Rectification and Phase Width Modulation}

\subsection{Digital Synchronous Rectification (DSR)}

The secondary synchronous rectifier circuit is illustrated in Figure 8. The MOSFET is turned on when the anti-paralleled diode current is increasing. Then, the current flows through MOSFET. When the current is below a turn-off threshold, the MOSFET is turned off.

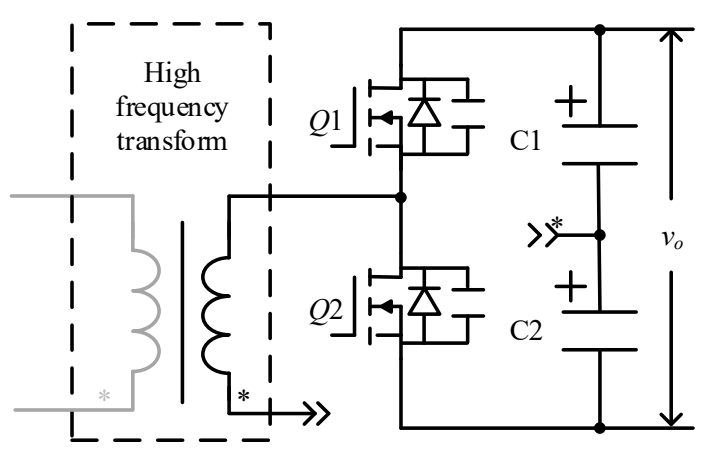

Figure 8. Synchronous rectifier circuit.

The waveform of current and voltage is illustrated in Figure 9. At the beginning of a period, the drain to source voltage $V_{\mathrm{ds}}$ is equal to the turn-on voltage drop of the anti-parallel diode. The $V_{\mathrm{ds}}$ drops to the turn-on voltage drop of MOSFET when SR is working. As a result, the $V_{\mathrm{ds}}$ of MOSFET is obviously less than the $V_{\mathrm{ds}}$ of the anti-parallel diode. The power loss in this process is caused by the current flow through the MOSFET, rather than the diode.
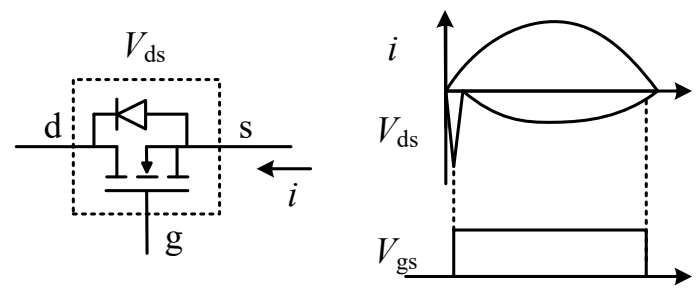

Figure 9. The working waveform of synchronous rectification.

\subsection{Phase Width Modulation Strategy}

Figure 10 shows the control block diagram of the phase width modulation (PhWM) strategy. In respect to the traditional control method, the switching frequency is the control parameter according to the main circuit parameters [28]. However, the PhWM strategy used in the H-bridge DC-DC converter also applies to the LLC DC-DC converter. The output voltage can be regulated by the PhWM strategy, which realizes the voltage regulation by changing the duty cycle. When the switching frequency is the 
second resonant frequency $f_{r}$, the increase of duty cycle is equivalent to the decrease of frequency. The ZVS can be achieved without adding other auxiliary devices.

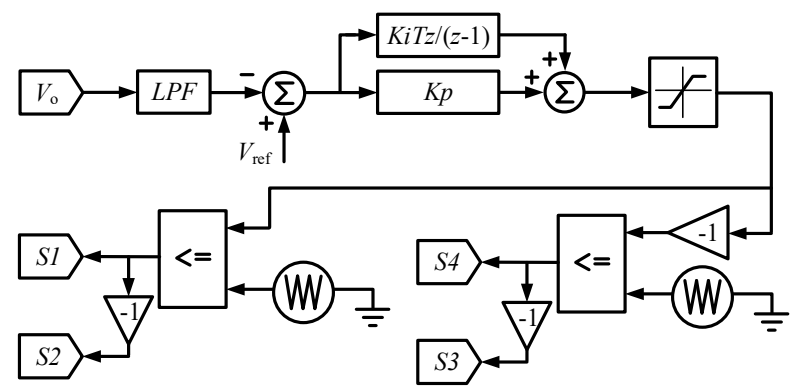

Figure 10. Control block diagram of phase width modulation (PhWM).

The comparison between PhWM and phase frequency modulation (PFM) is shown in Figure 11. On the basis of the normal control, the PhWM strategy can reduce the input power energy, which can stabilize the output voltage. By adding the status when $S_{1}, S_{3}$ and $S_{2}, S_{4}$ turn on simultaneously, the resonant network constitutes a short circuit state, so that the input voltage and the resonant network are isolated. The load energy can be reduced.

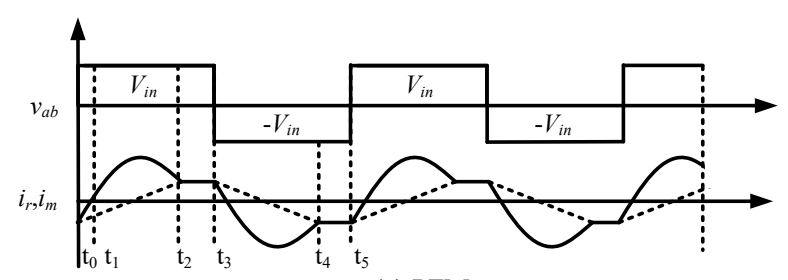

(a) PFM

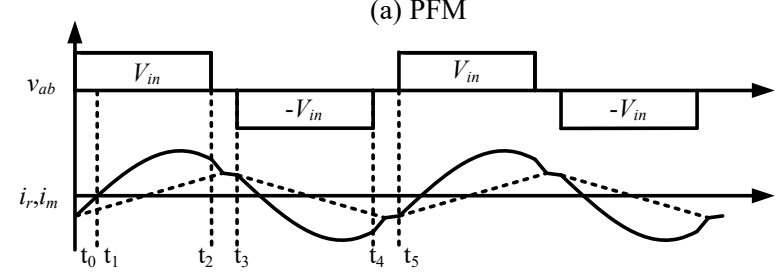

(b) PhWM

Figure 11. Comparison between PhWM and PFM. (a) The principle of PFM; (b) The principle of PhWM.

Based on engineering experience, there may be the input overvoltage and output overvoltage when the converter is in operation. In general, input overvoltage can be avoided by increasing the capacitance on the input side [29]. However, the output voltage would be overvoltage when the load changed, which would damage SiC MOSFET. Some control methods can be used to avoid output overvoltage [30-32]. In this paper, a variable duty cycle modulation is designed in Figure 12. The duty cycle is increased slowly to normal working conditions, which can effectively reduce overvoltage during the start-up process. In addition, the driver and hardware protection circuits can also protect $\mathrm{SiC}$ MOSFET from the damage of the short circuit.

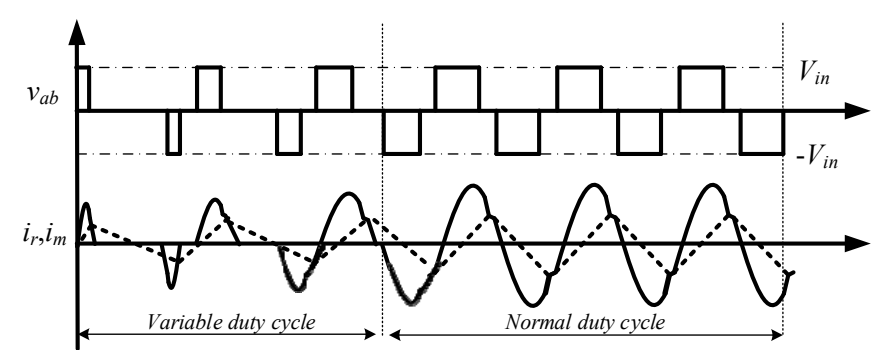

Figure 12. Variable duty cycle modulation. 


\section{Simulation and Experiment}

\subsection{The Simulation of the LLC DC-DC Converter}

For verifying the correctness of the proposed system and control strategy, a simulation model is established in MATLAB/Simulink. The simulation parameters are listed in Table 1, and are calculated by a mathmetical model of the LLC DC-DC converter. The input voltage, output voltage, and rated power correspond with the actual engineering parameters.

Table 1. Simulation parameters of the converter.

\begin{tabular}{cc}
\hline Parameter & Value \\
\hline Input Voltage & $1000 \mathrm{~V}-1800 \mathrm{~V}$ \\
Output Voltage & $560 \mathrm{~V}$ \\
Rated Power & $60 \mathrm{kw}$ \\
Magnetizing Inductance & $3 \mathrm{mH}$ \\
Leakage Inductance & $742.4 \mu \mathrm{H}$ \\
Resonant Capacitance & $3.8 \mu \mathrm{F}$ \\
Switch Frequency & $3000 \mathrm{~Hz}$ \\
\hline
\end{tabular}

The simulation waveforms of transformer and resonant tanks are shown in Figure 13. By comparing the position of the voltage and current zero crossing points, the ZVS of primary switches is realized in Figure 13a and the ZCS of secondary switches is achieved in Figure 13b.
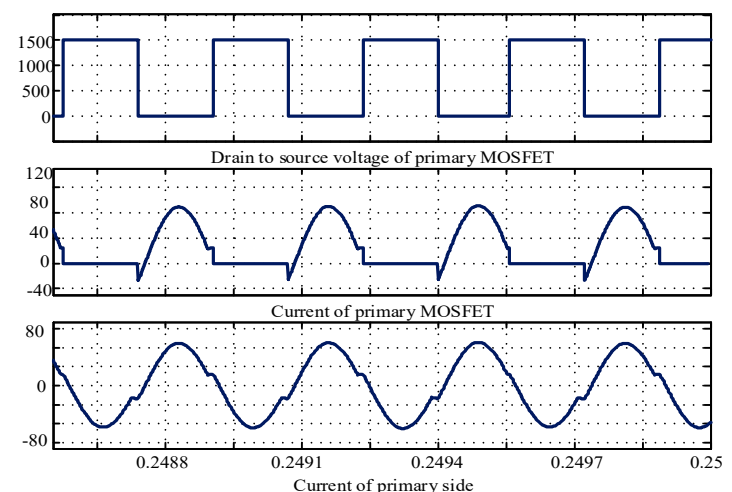

(a)

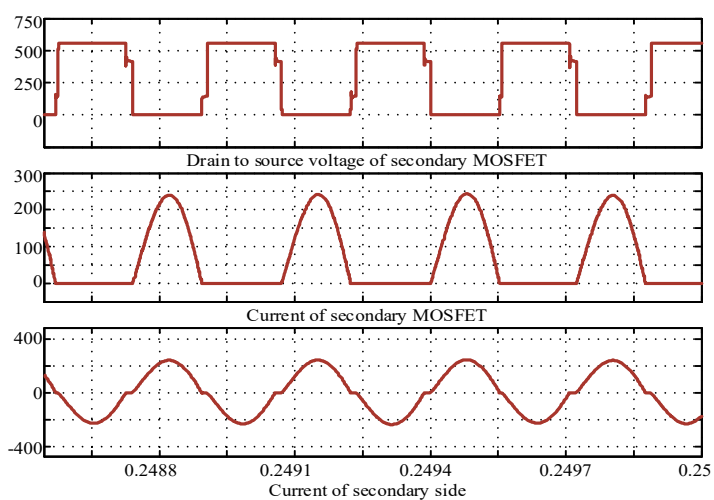

(b)

Figure 13. The waveforms of the LLC DC-DC converter. (a) the ZVS of primary switches. (b) the ZCS of secondary switches.

In order to further verify the validly of dynamic performance, the simulation is completed with different output power and input voltage. Every $0.25 \mathrm{~s}$, the output power is changed generally between $50 \%$ and $100 \%$. From $0 \mathrm{~s}$ to $1.5 \mathrm{~s}$, the input voltage fluctuates from $1500 \mathrm{~V}$ to $1000 \mathrm{~V}$ and $1800 \mathrm{~V}$. As is shown in Figure 14, the output voltage can be regulated to the rated value and the well-dynamic performance is derived.

\subsection{The Experiment of the LLC DC-DC Converter}

The circuit parameters are listed in Table 2. The controller of the system is FPGA EP4CE10F17, which provides switching signals to all $\mathrm{SiC}$ MOSFETs. The experimental waveforms of voltage and resonant current are shown in Figure 15, where the input voltage is $50 \mathrm{~V}$ and the output current is $2 \mathrm{~A}$. The converter completes the conditions of the primary ZVS and the secondary ZCS. In Figure 15b, the DC output voltage of the LLC DC-DC converter is twice as large as the input voltage. 


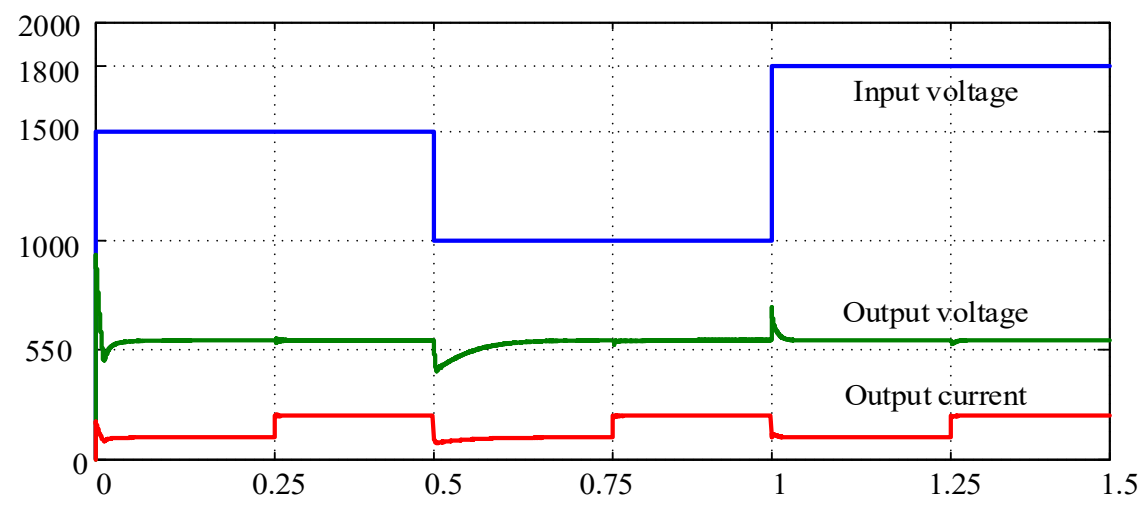

Figure 14. Dynamic performance of output voltage.

Table 2. Circuit parameters of the converter.

\begin{tabular}{cc}
\hline Parameter & Value \\
\hline SiC MOSFET & CREE C3M0065090 \\
Controller & FPGA EP4CE10F17 \\
Input Voltage & $50 \mathrm{~V}$ \\
Transformer Turns & $1: 1$ \\
Magnetizing Inductance & $1.2 \mathrm{mH}$ \\
Leakage Inductance & $98 \mu \mathrm{H}$ \\
Resonant Capacitance & $10 \mu \mathrm{F}$ \\
Switch Frequency & $3000 \mathrm{~Hz}$ \\
Experimental Temperature & $20^{\circ} \mathrm{C}$ \\
\hline
\end{tabular}

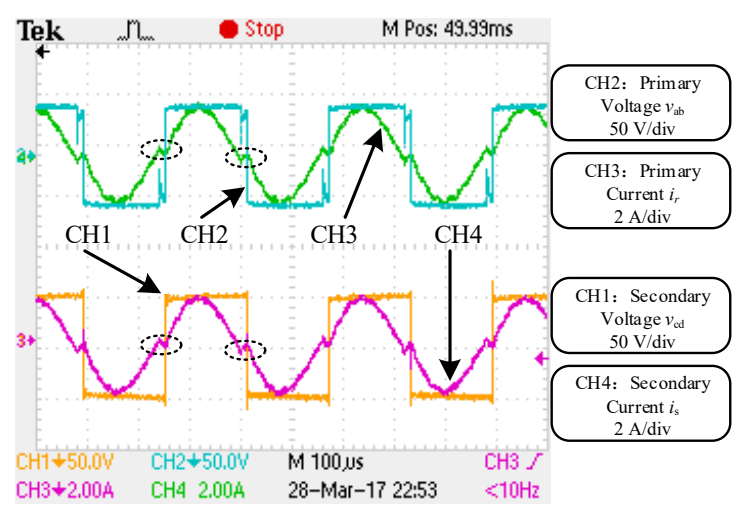

(a)

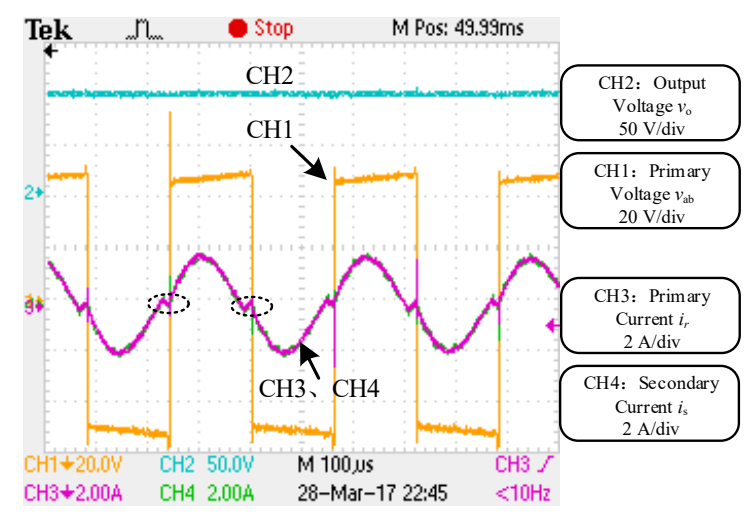

(b)

Figure 15. LLC DC-DC converter with fixed frequency: (a) CH1: Primary voltage, $v_{a b}, \mathrm{CH} 2$ : Secondary voltage, $v_{c d}, \mathrm{CH} 3$ : Primary current, $i_{r}$, and CH4: Secondary current, $i_{s}$. (b) CH1: Primary voltage, $v_{a b}$, $\mathrm{CH} 2$ : Output voltage, $v_{0}, \mathrm{CH} 3$ : Primary current, $i_{r}$, and CH4: Secondary current, $i_{s}$.

Figure 16 shows the picture of the primary side experiment platform. The temperature of each $\mathrm{SiC}$ MOSFET device in the experiment was further measured using an optical temperature gauge. The primary side $\mathrm{SiC}$ MOSFETs are $21^{\circ} \mathrm{C}$. Because the experimental temperature is $20^{\circ} \mathrm{C}$, the temperature rise of primary side $\mathrm{SiC}$ MOSFETs is only $1{ }^{\circ} \mathrm{C}$. As a result, the primary loss is low. 


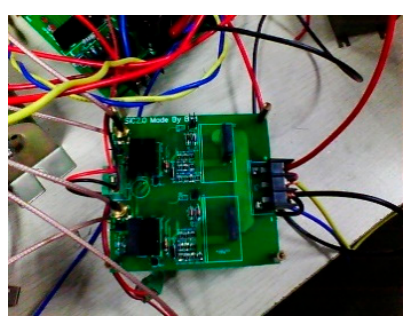

(a)

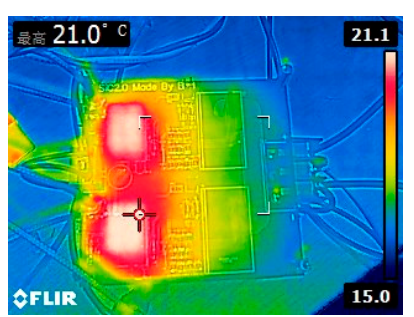

(b)

Figure 16. Primary side main circuit and thermal image. (a) the experimental photographs of primary side in $20^{\circ} \mathrm{C}$. (b) the temperature rise of primary side.

Figure 17 shows the picture of the secondary side experiment platform. As is shown in Figure 17b, the temperature of the secondary side SiC MOSFETs is $37.1^{\circ} \mathrm{C}$. At this time, $\mathrm{SR}$ is not used in the secondary side SiC MOSFET. When the secondary side SiC MOSFETs are working, there will be a large current flowing through the parallel diode. Due to the equivalent impedance of the SiC MOSFET anti-parallel diode being large, the loss of the secondary side SiC MOSFET is high.

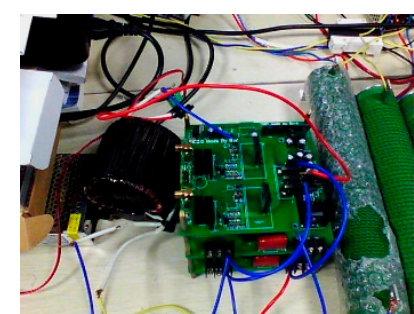

(a)

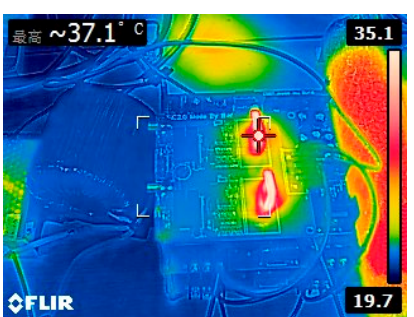

(b)

Figure 17. Secondary side circuit and thermal image. (a) the experimental photographs of secondary side in $20^{\circ} \mathrm{C}$. (b) the thermal image of secondary side.

\subsection{The Experiment of Synchronous Rectification}

Figure 18 is the waveform of synchronous rectification. The working states in the time interval of $t_{0}-t_{4}$ are analyzed. No drive signal is given at $t_{0}$. At $t_{1}$, the driving signal of the $Q_{1}$ is at a high level and the $Q_{1} \operatorname{SiC}$ MOSFET is on. At $t_{2}$, the current through the $Q_{1}$ is 0 and the driving signal of the $Q_{1}$ are at a low level. At $t_{3}$, the current of $Q_{2}$ has just been established. At this moment, no drive signal is given. Until $t_{4}$, the drive signal of $Q_{2}$ is high.

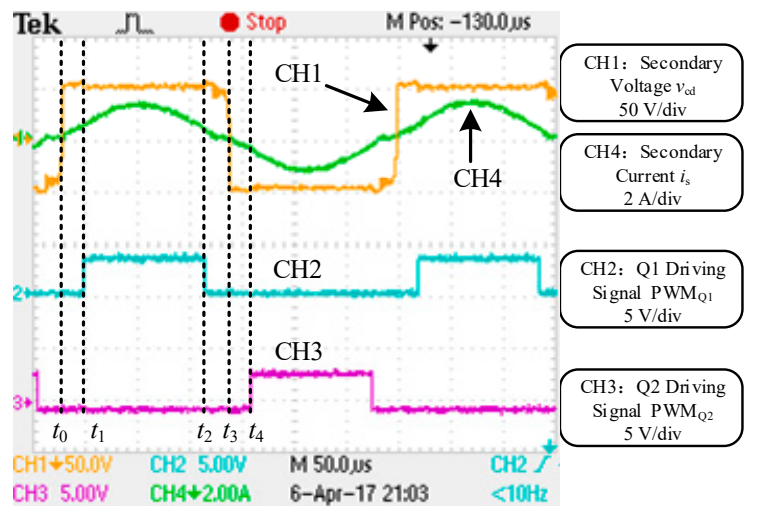

Figure 18. Synchronous rectification waveform. $\mathrm{CH} 1$ : Secondary voltage, $v_{c d}, \mathrm{CH} 2$ : Upper SiC MOSFET Driving Signal, CH3: Under SiC MOSFET driving signal, and CH4: Secondary current, $i_{s}$.

Figure 19 shows the thermal image of synchronous rectification. To compare the advantages of synchronous rectification, the SR is used in upper SiC MOSFET but it is not used in under SiC MOSFET. 
From Figure 19a, it can be seen that the temperature of the upper $\mathrm{SiC}$ MOSFET is $21.9^{\circ} \mathrm{C}$. Meanwhile, the temperature of the under $\mathrm{SiC}$ MOSFET is $31.1^{\circ} \mathrm{C}$, which is shown in Figure $19 \mathrm{~b}$. By contrasting Figure 19a,b, the secondary side SiC MOSFETs has higher efficiency with synchronous rectification.

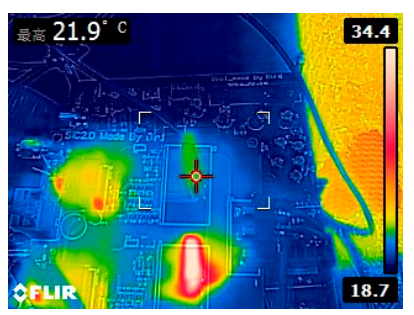

(a)

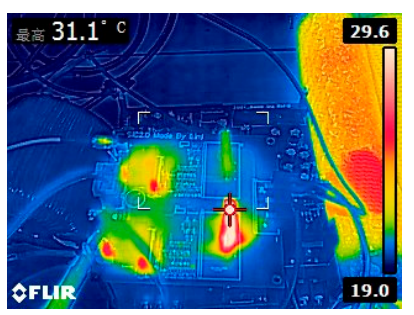

(b)

Figure 19. Thermal image of synchronous rectification. (a) the thermal image of the upper SiC MOSFET. (b) the thermal image of the under $\mathrm{SiC}$ MOSFET.

\subsection{The Experiment of Phase Width Modulation Strategy}

The experiment waveform of PhWM is shown in Figure 20. When the angle of the phase shift is small, the feature waveform remains apparent. As is shown in Figure 20a, the primary voltage is ZVS and the secondary current is ZCS. With the angle of the phase shift increasing, the primary voltage remains ZVS and the secondary current also remains ZCS, which is shown in Figure 20b. Because the current is increasing, the secondary side current has little fluctuations.

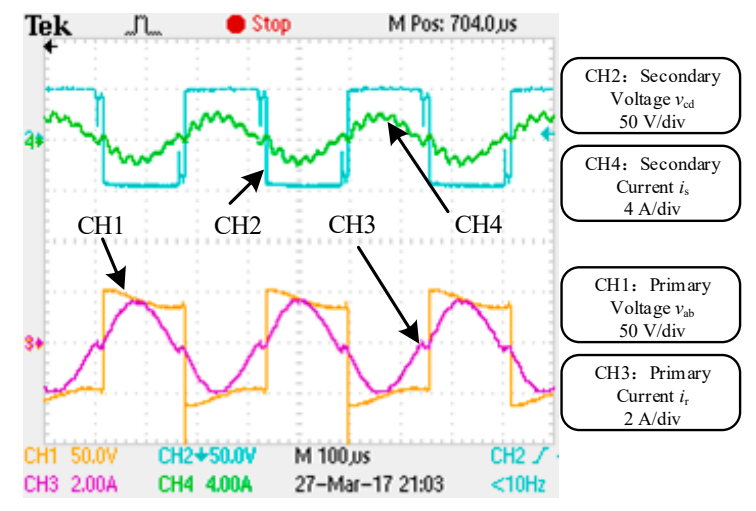

(a)

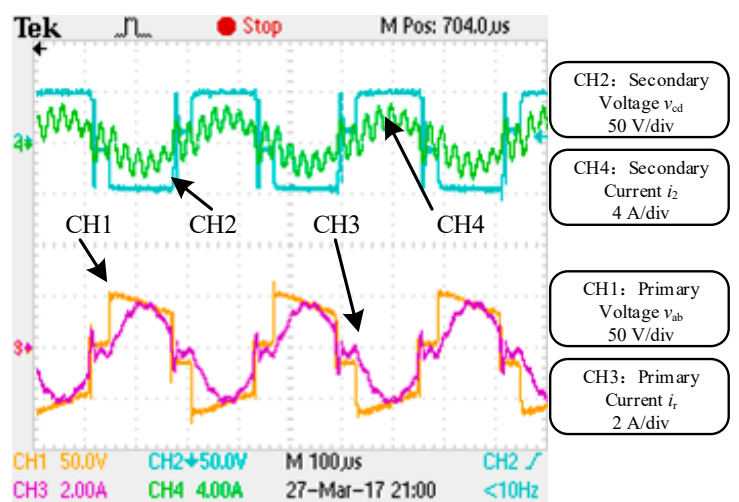

(b)

Figure 20. The experiment waveform of phase shift control. (a) $\mathrm{CH} 1$ : Primary voltage, $v_{a b}, \mathrm{CH} 2$ : Secondary voltage, $v_{c d}, \mathrm{CH} 3$ : Primary current, $i_{r}$, and CH4: Secondary current, $i_{s}$. (b) CH1: Primary voltage, $v_{a b}, \mathrm{CH} 2$ : Secondary voltage, $v_{c d}, \mathrm{CH} 3$ : Primary current, $i_{r}$, and CH4: Secondary current, $i_{s}$.

As is shown in Figure 21, when the phase shift angle continues increasing, the resonance time of the current of $L_{\mathrm{r}}$ and $C_{\mathrm{r}}$ is getting shorter. As a result, the lesser the input power to the resonator power supply, the smaller the voltage output.

In order to verify the correctness of the control strategy, the load changed experiment is designed in this paper. Figure 22 is the waveform that the LLC DC-DC converter is from no load to $100 \Omega$. As is shown in Figure 22, the output voltage is stable with no load. When the load is put on, the output voltage would be reduced. To keep the voltage constant, the duty cycle of the switch would be increased to regulate the voltage. After a period of adjustment, the output voltage remains stable. As is shown in Figure 22, the LLC characteristic is still clear after load changed. At the same time, the ZVS is retained. The correctness of the phase width modulation is verified. 


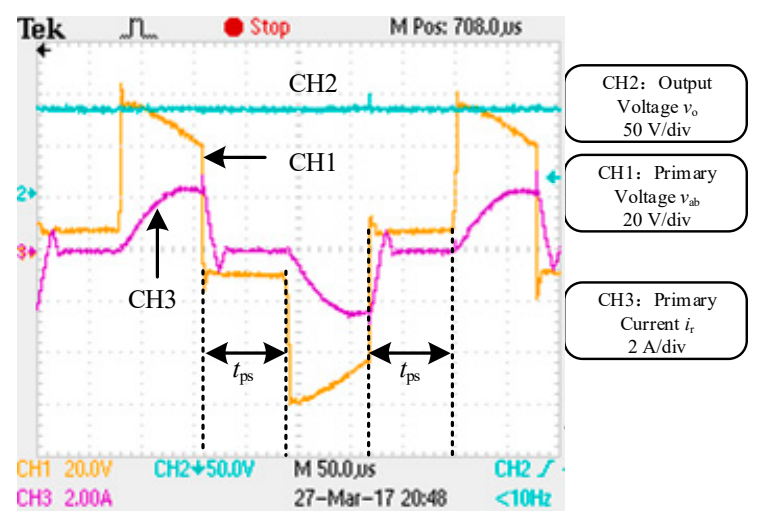

Figure 21. The experiment waveform of increasing shift angle. $\mathrm{CH} 1$ : Primary voltage, $v_{\mathrm{ab}}, \mathrm{CH} 2$ : Output voltage, $v_{\mathrm{o}}$, and $\mathrm{CH} 3$ : Primary current, $i_{r}$.

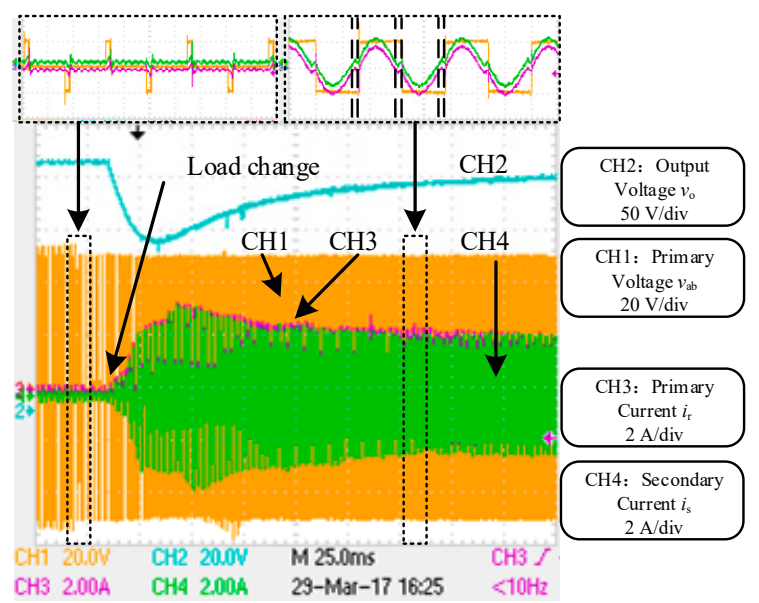

Figure 22. Load changed experiment. $\mathrm{CH} 1$ : Primary voltage, $v_{a b}, \mathrm{CH} 2$ : Output voltage, $v_{0}, \mathrm{CH}$ : Primary current, $i_{r}$, and $\mathrm{CH} 4$, Secondary current, $i_{s}$.

\subsection{Efficiency Analysis}

The efficiency curves under the different experimental conditions are illustrated in Figure 23 and different loads are selected as test points, including 25\%,30\%, 50\%, 75\%, and full load. There are three different converters tested for the efficiency, which are the SiC MOSFET with SR, SiC MOSFET, and Si IGBT. Si IGBT is the switching device in the existing magnetic levitation power supply system. Compared with these efficiency data of five groups, the efficiency under the SR are obviously higher. The power loss on the secondary side has been saved with SR. Finally, the efficiency of light load is over $90 \%$, while the efficiency of rated load is about $98 \%$ under the proposed strategy.

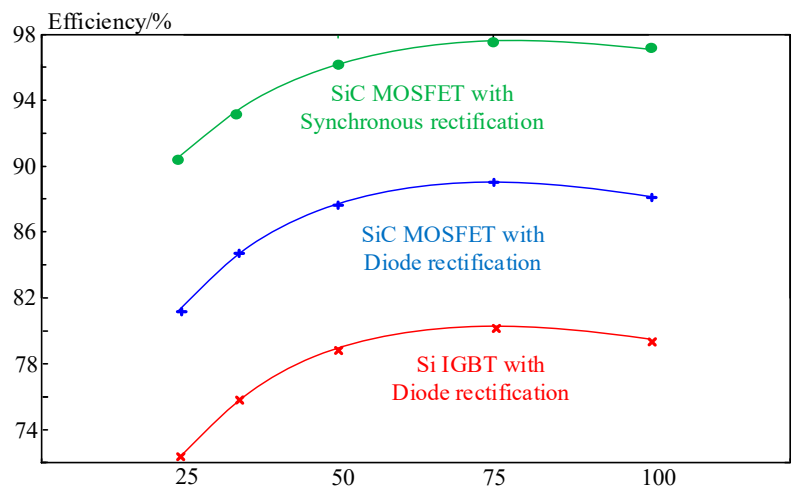

Figure 23. Efficiency curve. 
The results of power loss comparison among Si IGBT, SiC MOSFET, and SiC MOSFET with SR are shown in Figure 24. The loss of the LLC DC-DC converter is composed mainly of primary transistor loss, secondary transistor loss, transformer core loss, transformer wire loss, and capacitor loss. In this paper, the controller loss is ignored.

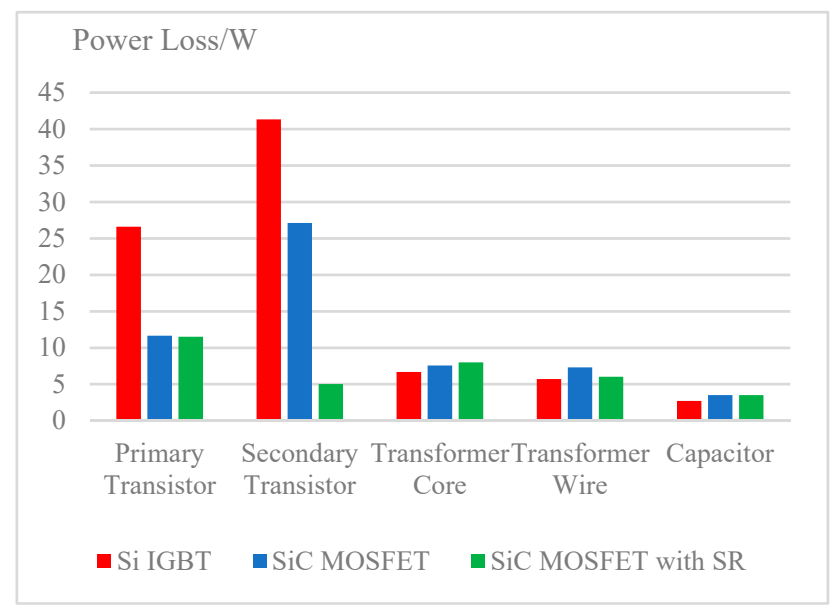

Figure 24. Power loss distribution.

In traditional magnetic levitation power supply systems, primary transistor loss and secondary transistor loss account for a large proportion of the system loss. When Si IGBT is replaced by SiC MOSFET, the primary transistor loss and secondary transistor loss is reduced. At this time, the secondary transistor loss still accounts for a large proportion of the system loss. When SR is used in the SiC MOSFET, the secondary transistor loss is significantly reduced. However, with the frequency increasing, transformer core loss, transformer wire loss, and capacitor loss would increase. According to the data analysis, the efficiency of the new auxiliary power supply system improved significantly.

Figure 25 is the experimental structure of the LLC DC-DC converter. In order to analyze the efficiency and the power loss correctly, the DC power and the electronics load are used in this paper. The input power is calculaed by the DC power, which model is IT6615D. The output power is calculaed by the electronics load, which model is IT8902E. In this way, the efficiency and the power loss can be calculaed by the input power and the output power.

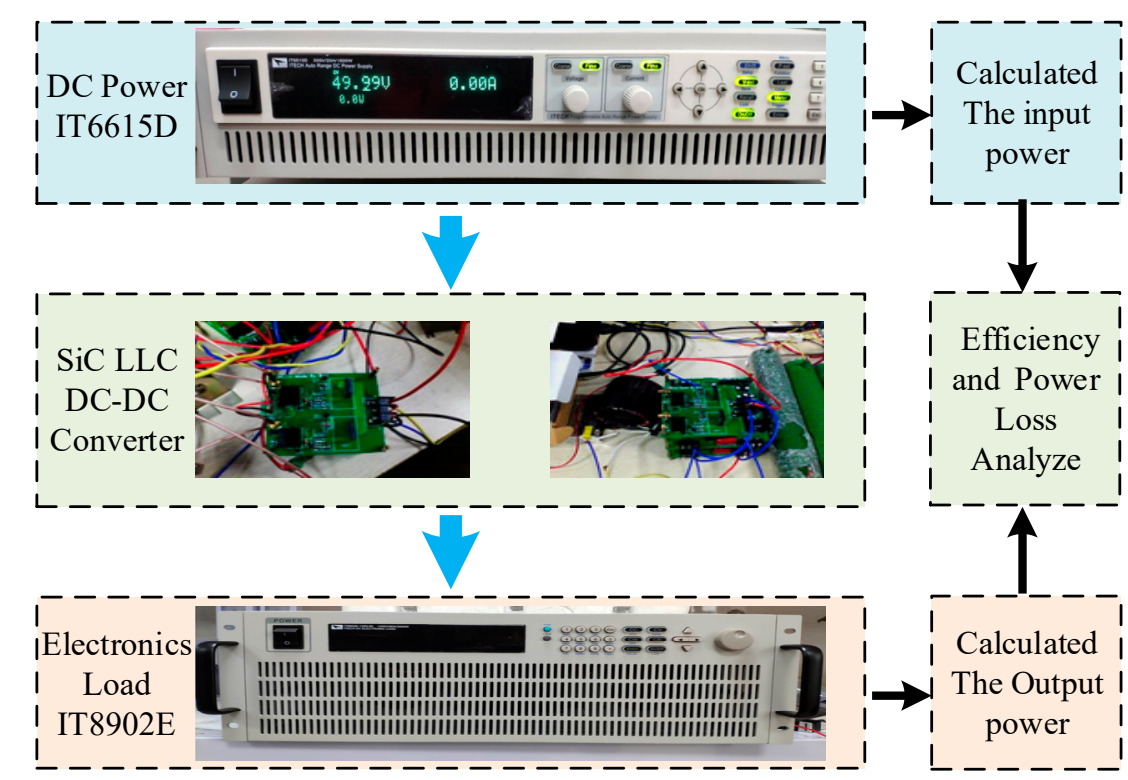

Figure 25. Experimental structure of the LLC DC-DC converter. 


\section{Conclusions}

This paper proposed a new auxiliary power supply system of magnetic levitation based on the LLC DC-DC converter, whose switches are SiC MOSFET. For improving the efficiency of the converter, the SR used in the secondary side of the LLC DC-DC converter was designed. According to the experiment results and the data analysis of the efficiency, the following advantages can be obtained. First, a new auxiliary power supply system of magnetic levitation based on the LLC DC-DC converter can realize the ZVS and ZCS, which will reduce the system loss. Then, when SR is applied to the SiC MOSFET, the secondary transistor loss is significantly reduced. In this way, the prototype demonstrates 98\% peak efficiency. According to the data analysis of the loss breakdown comparison among $\mathrm{Si}$ IGBT, SiC MOSFET, and SiC MOSFET with SR, primary transistor loss and secondary transistor loss account for a large proportion of the system loss in a traditional magnetic levitation power supply system. Finally, due to the applications of LLC topology, SiC MOSFET, and SR, the efficiency of the new auxiliary power supply system can be significantly improved.

Author Contributions: All the authors contributed to this work. X.H. and Z.Z. analyzed the strategy and conceived the experiment; Z.Z. performed the experiment and wrote the paper; X.H. analyzed the data and contributed the experimental prototype. All authors have read and agreed to the published version of the manuscript.

Funding: This work was supported by the Science and technology program of Sichuan Province (Grant No. 2019YJ0241) and research foundation of National Rail Transit Electrification and Automation Engineering Technique Research Center (Grant No. NEEC-2017-A01).

Acknowledgments: We wish to thank the timely help given by School of Electrical Engineering, Southwest Jiaotong University and National Rail Transit Electrification and Automation Engineering Technique Research Center.

Conflicts of Interest: The authors declare no conflict of interest.

\section{References}

1. Ronanki, D.; Singh, S.; Williamson, S. Comprehensive Topological Overview of Rolling Stock Architectures and Recent Trends in Electric Railway Traction Systems. IEEE Trans. Transp. Electron. 2017, 3, 724-738. [CrossRef]

2. Chung, Y.; Lee, C.; Kim, D.; Kang, H.; Park, Y.; Yoon, Y. Conceptual Design and Operating Characteristics of Multi-Resonance Antennas in the Wireless Power Charging System for Superconducting MAGLEV Train. IEEE Trans. Appl. Supercond. 2017, 27, 1-5. [CrossRef]

3. Vahedi, H.; Al-Haddad, K. A novel multilevel multi-ouput bidirectional active buck PFC rectifier. IEEE Trans. Ind. Electron. 2016, 63, 5442-5450. [CrossRef]

4. Meng, T.; Song, Y.; Wang, Z.; Ben, H.; Li, C. Investigation and Implementation of an Input-Series Auxiliary Power Supply Scheme for High-Input-Voltage Low-Power Applications. IEEE Trans. Power Electron. 2018, 33, 437-447. [CrossRef]

5. Chang, F.; Ilina, O.; Lienkamp, M.; Voss, L. Improving the Overall Efficiency of Automotive Inverters Using a Multilevel Converter Composed of Low Voltage Si MOSFETs. IEEE Trans. Power Electron. 2019, 34, 3586-3602. [CrossRef]

6. Swamy, M.M.; Kang, J.; Shirabe, K. Power Loss, System Efficiency, and Leakage Current Comparison Between Si IGBT VFD and SiC FET VFD with Various Filtering Options. IEEE Trans. Ind. Appl. 2015, 51, 3858-3866. [CrossRef]

7. Hazra, S.; De, A.; Cheng, L.; Palmour, J.; Schupbach, M.; Hull, B.A.; Allen, S.; Bhattacharya, S. High Switching Performance of 1700-V, 50-A SiC Power MOSFET Over Si IGBT/BiMOSFET for Advanced Power Conversion Applications. IEEE Trans. Power Electron. 2016, 31, 4742-4754. [CrossRef]

8. Fabre, J.; Ladoux, P. Parallel Connection of 1200-V/100-A SiC-MOSFET Half-Bridge Modules. IEEE Trans. Ind. Appl. 2016, 52, 1669-1676. [CrossRef]

9. Hazra, S.; Madhusoodhanan, S.; Moghaddam, G.K.; Hatua, K.; Bhattacharya, S. Design Considerations and Performance Evaluation of 1200-V 100-A SiC MOSFET-Based Two-Level Voltage Source Converter. IEEE Trans. Ind. Appl. 2016, 52, 4257-4268. [CrossRef]

10. Wang, L.; Zhu, Q.; Yu, W.; Huang, A.Q. A Medium-Voltage Medium-Frequency Isolated DC-DC Converter Based on 15-kV SiC MOSFETs. IEEE Trans. Power Electron. 2017, 5, 100-109. [CrossRef] 
11. Gwan-Bon, K.; Gun-Woo, M.; Myung-Joong, Y. New zero-voltage-switching phase-shift full-bridge converter with low conduction losses. IEEE Trans. Ind. Electron. 2005, 52, 228-235. [CrossRef]

12. Shi, Y.; Yang, X. Zero-Voltage Switching PWM Three-Level Full-Bridge DC-DC Converter with Wide ZVS Load Range. IEEE Trans. Power Electron. 2013, 28, 4511-4514. [CrossRef]

13. Kanamarlapudi, V.R.K.; Wang, B.; Kandasamy, N.K.; So, P.L. A New ZVS Full-Bridge DC-DC Converter for Battery Charging with Reduced Losses Over Full-Load Range. IEEE Trans. Ind. Appl. 2018, 54, 571-579. [CrossRef]

14. Liu, R.; Lee, C.Q. Series resonant converter with third-order commutation network. IEEE Trans. Power Electron. 1992, 7, 462-468. [CrossRef]

15. Steigerwald, R.L. A comparison of half-bridge resonant converter topologies. IEEE Trans. Power Electron. 1988, 4, 174-182. [CrossRef]

16. Martin-Ramos, J.A.; Pernia, A.M.; Diaz, J.; Nuno, F.; Martinez, J.A. Power Supply for a High-voltage Application. IEEE Trans. Power Electron. 2008, 7, 1608-1619. [CrossRef]

17. Shakib, S.; Mekhilef, S. A Frequency Adaptive Phase Shift Modulation Control Based LLC Series Resonant Converter for Wide Input Voltage Applications. IEEE Trans. Power Electron. 2017, 11, 8360-8370. [CrossRef]

18. Lee, I.; Moon, G. The k-Q Analysis for an LLC Series Resonant Converter. IEEE Trans. Power Electron. 2014, 29, 13-16. [CrossRef]

19. Lin, R.; Huang, L. Efficiency Improvement on LLC Resonant Converter Using Integrated LCLC Resonant Transformer. IEEE Trans. Ind. Appl. 2018, 54, 1756-1764. [CrossRef]

20. Feng, W.; Lee, F.C.; Mattavelli, P. Optimal Trajectory Control of LLC Resonant Converters for LED PWM Dimming. IEEE Trans. Power Electron. 2014, 29, 979-987. [CrossRef]

21. Fei, C.; Li, Q.; Lee, F.C. Digital Implementation of Adaptive Synchronous Rectifier (SR) Driving Scheme for High-Frequency LLC Converters with Microcontroller. IEEE Trans. Power Electron. 2018, 33, 5351-5361. [CrossRef]

22. Mohammadi, M.; Ordonez, M. Synchronous Rectification of LLC Resonant Converters Using Homopolarity Cycle Modulation. IEEE Trans. Ind. Electron. 2019, 66, 1781-1790. [CrossRef]

23. Feng, W.; Mattavelli, P.; Lee, F.C. Pulsewidth Locked Loop (PWLL) for Automatic Resonant Frequency Tracking in LLC DC-DC Transformer (LLC -DCX). IEEE Trans. Power Electron. 2013, 28, 1862-1869. [CrossRef]

24. Saket, M.; Shafiei, N.; Ordonez, M. LLC Converters with Planar Transformers Issues and Mitigation. IEEE Trans. Power Electron. 2017, 32, 4524-4542. [CrossRef]

25. Kim, K.; Youn, H.; Baek, J.; Jeong, Y.; Moon, G. Analysis on Synchronous Rectifier Control to Improve Regulation Capability of High-Frequency LLC Resonant Converter. IEEE Trans. Power Electron. 2018, 33, 7252-7259. [CrossRef]

26. Zhang, J.; Hurley, W.G.; Wölfle, W.H. Gapped Transformer Design Methodology and Implementation for LLC Resonant Converters. IEEE Trans. Ind. Appl. 2016, 52, 342-350. [CrossRef]

27. Yan, Q.; Yuan, X.; Geng, Y.; Charalambous, A.; Wu, X. Performance Evaluation of Split Output Converters with SiC MOSFETs and SiC Schottky Diodes. IEEE Trans. Power Electron. 2017, 32, 406-422. [CrossRef]

28. Fang, Z.; Wang, J.; Duan, S.; Xiao, L.; Hu, G.; Liu, Q. Rectifier Current Control for an LLC Resonant Converter Based on a Simplified Linearized Model. Energies 2018, 11, 579. [CrossRef]

29. Wang, H.; Li, Z. A PWM LLC Type Resonant Converter Adapted to Wide Output Range in PEV Charging Applications. IEEE Trans. Power Electron. 2018, 33, 3791-3801. [CrossRef]

30. Zou, S.; Lu, J.; Mallik, A.; Khaligh, A. Bi-Directional CLLC Converter with Synchronous Rectification for Plug-In Electric Vehicles. IEEE Trans. Ind. Appl. 2018, 54, 998-1005. [CrossRef]

31. Han, P.; He, X.; Ren, H.; Zhao, Z.; Peng, X. Research on High Efficiency LLC DC-DC Converter Based on SiC MosFet. In Proceedings of the IPEC-ECCE-Asia, Niigata, Janpan, 20-24 May 2018. [CrossRef] 
32. Han, P.; He, X.; Ren, H.; Wang, Y.; Peng, X.; Shu, Z.; Gao, S.; Wang, Y.; Chen, Z. Fault Diagnosis and System Reconfiguration Strategy of a Single-Phase Three-Level Neutral-Point-Clamped Cascaded Inverter. IEEE Trans. Ind. Appl. 2019, 55, 3863-3876. [CrossRef]

33. Peng, X.; Liu, X.; Yang, G.; Gao, L. Capacitors Energy Strategy Based Cascaded H-Bridge Converter for DC Port Failures. J. Power Electron. 2019, 5, 1133-1141. [CrossRef]

(C) 2019 by the authors. Licensee MDPI, Basel, Switzerland. This article is an open access article distributed under the terms and conditions of the Creative Commons Attribution (CC BY) license (http://creativecommons.org/licenses/by/4.0/). 